\title{
Slze generalization in children as a function of test method and age?
}

\author{
JEFFREY S. LANDAU, Adelphi Univer-
} sity, Garden City, L.I., N. Y. 11530

Children, ranging in age from $31 / 2-41 / 2$ years and $41 / 2-51 / 2$ years were provided with successive discrimination training in which $S+$ was a white square on a black background and $S$ - was a black background. Bidirectional size generalization testing with either a "booster" or "instructional" method indicated that (1) test method did not differentially affect generalization patterns, (2) younger children responded maximally to all test stimuli while spontaneously labeling the size stimuli "big" and "little". (3) older children generated a group gradient composed of one subgroup who responded to all test stimuli and a second subgroup who responded to $S+$ only; (4) posttest verbal behavior suggested that the size cue controlled St-only responding while controlling stimuli associated with flat patterns were color ("white") and form ("window"). The results drew attention to stimulus selection processes in the stimulus generalization experiment.

Children ranging in age from $31 / 2-41 / 2$ years exhibit flat line orientation generalization patterns (Landau, 1968a, b) while older children exhibit spatial [(6-12 years) Jeffrey \& Skager, 1962; Mednick \& Lehtinen, 1957; Tempone, 1965, 1966], brightness [(4-6 years) Spiker, 1956b], and color [(4-51/2 years) Spiker, 1956a] gradients. One difference among these studies, in addition to age, is that the youngest children were tested with an "instructional" me thod while the older Ss were provided with a "booster" procedure. The purpose of Experiment 1 was to determine whether generalization test patterns in young children are related to the method of testing. It was expected that if young children were to exhibit response decrements to test stimuli they would be more likely to do so with the "booster" method. The reason is that this procedure involves discrimination training in which $\mathrm{S}+$ is intermittently reinforced and test stimuli are nonreinforced.

The size continuum was utilized in the present experiments. The purpose was twofold: first, to assess the generality of the line orientation findings; and second, to examine performance on a dimension frequently employed in transposition studies in which gradients are postulated to underlie near transposition (Hebert \& Krantz, 1965).

\section{EXPERIMENT \\ Subjects}

Twenty-one children, in attendance at nursery schools in Nassau County, Long Island, New York, and ranging in age from $31 / 2$ to $4 \frac{1}{2}$ years, served as $S s^{1}$

$$
\text { Apparatus }
$$

The apparatus consisted of a flat black three-sided display box, $20 \times 30 \times 15$ in. Cut into one side of the face of the display box was a single 10-in. square window behind which was a clip-type card holder. In addition, a black curtain ( $19 \times 33$ in.) was used to veil the face of the apparatus during intertrial intervals.

The stimuli were constructed by pasting white paper squares on $11 \times 14 \mathrm{in}$. black posterboard cards. The surface areas of the seven squares were $5.94 \mathrm{sq}$ in. $(-3)$ $8.27 \mathrm{sq}$ in. $(-2), \quad 11.18 \mathrm{sq}$ in. $(-1)$, $16.00 \mathrm{sq}$ in. (0), $21.68 \mathrm{sq}$ in. $(+1)$, $30.59 \mathrm{sq}$ in. (+2), and $42.75 \mathrm{sq}$ in. (+3).

\section{Procedure}

In the first phase of the experiment all Ss were given successive discrimination training in which $S+$ was $16.00 \mathrm{sq}$ in. and $S_{--}$was a black posterboard card (B). The verbal designator of $\mathrm{S}+$ was the nonsense name "vec." S responded by saying "yes" if he thought the picture (S+ or $\mathbf{S}_{-}$) had the name "vec" and by saying "no" if he thought it did not. E confirmed a correct response but said nothing if $S$ made an error.

The training stimuli were presented in blocks of 10 trials, half of which contained St presentations and half of which contained S- presentations. Ss were randomly assigned to either of two fixed sequences of four blocks, each of which contained a different Gellerman order. Criterion was errorless performance on nine consecutive training trials. If $S$ failed to attain criterion after 40 trials he was eliminated from the experiment. One $S$ was eliminated on this basis. Thus, $10 \mathrm{Ss}$ were available for generalization testing in each method subgroup.

Immediately after discrimination training, the successive method of generalization testing was begun. Ss in the "instructional" test method group were informed that they were now going to be shown a few more pictures and that they should continue as before except that they would no longer be told if they were right. Ss in the "booster" group began testing immediately.

The sequence and number of stimulus presentations for the "instructional" and "booster" groups were the same although several different individual test orders were used. For both groups there were three blocks of 10 trials each. Within each block there were four presentations of the training stimulus (St). For Ss in the "booster" group, "yes" responses to three of the four St presentations were reinforced while responses to the remaining $S+$ presentation (St test trial) was not. For $S s$ in the "instructional" group, one of the four St presentations within each block was predesignated (for scoring purposes) as the $S+$ test trial. For both groups, the remaining six trials contained six different size stimuli presented under extinction conditions. Thus, of the 10 stimuli in each block, 7 were considered test stimuli. Across blocks, S could respond a maximum of three times to each of these test stimuli.

\section{RESULTS \\ Generalization}

A two-factor mixed analysis of variance was performed on the generalization data. The main effects of test method $[F(1,8)=.23, \quad p>.05]$, test stimuli $[F(6,108)=1.86, p>.05]$, and the interaction between method and stimuli $[F(6,108)=.73, p>.05]$ were not statistically significant. These results indicate that most children in both test method conditions responded maximally to all generalization test stimuli.

During testing children spontaneously verbalized. In addition to responding "yes" they said, "yes, that's a big vec" or "that's a little vec." Computation of the number of "big" and "little" responses indicated group gradients from $S+$. As Fig. 1 shows, $S$ was not likely to respond to $+1,+2$, or +3 with "little" but did respond "big" least frequently to +1 and most frequently to +3 . The same group function was observed for "little" responses except that most of these occurred to -3 .

After testing, the children were asked what a "vec" was. Of the 20 children questioned, approximately half charac-

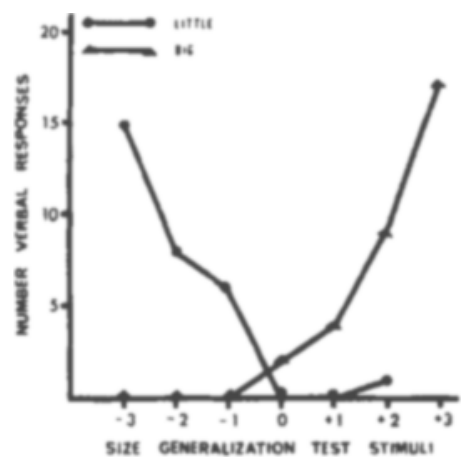

Fig. 1. Number of "big" and "little" responses to size generalization test stimuli for children $3 \frac{1}{2-4} 4 \frac{1}{2}$ years. 
terized "vec" as "white," five Ss said it was a "white square" or a "little white window," etc., and the remainder said it was "white and black."

\section{EXPERIMENT 2}

The failure to obtain size gradients in Experiment 1, with either the "booster" or "instructional" test procedure, raised the question of the relation between age and generalization. Most experiments which have reported generalization gradients with children have utilized somewhat older Ss than those of the present study. The purpose of Experiment 2 was to investigate the relation between age and size generalization patterns as a function of "booster" or "instructional" testing and under conditions in which the test stimuli were highly discriminable.

\section{Method}

Experiment 2 was the same as Experiment 1 except in the following ways: (1) Twenty children ranging in age from $31 / 2-4 \frac{1}{2}$ years were compared to 20 children ranging in age from $4 \frac{1}{2}-5 \frac{1}{2}$ years. (2) $S+$ (16.00 sq in.) and only two test stimuli were utilized. These test stimuli were indicated as -3 and +3 in Experiment 1 and are here indicated as -1 (5.94 sq in.) and +1 (42.75 sq in.). (3) St was presented six times and each test stimulus twice in each of three blocks of 10 trials.

\section{Results}

A 2 by 2 between-group analysis of variance (age and generalization method) was performed on errors in acquisition. The main effects of age $[F(1,36)=2.52$, $p>.05]$, and method $[F(1,36)=.99$, $\mathrm{p}>.05]$, and the interaction between age and method $[F(1,36)=1.24, p>.05]$ were not statistically significant. The means for the younger children were 3.6 and 1.8 in the "instructional" and "booster" subgroups, respectively; the means for the older children in the test method groups were 1.3 and 1.4 .

A three-factor (age, method, stimuli) mixed analysis of variance was performed on the generalization data. Only the main effect of stimuli $[F(2,72)=6.38, p<.01]$ and the interaction between age and stimuli $[F(2,72)=6.18, p<.01]$ were statistically significant. The results showed again that independent of test method young children responded maximally to all test stimuli (and, as in the first experiment, spontaneously verbalized "big" to +1 and "little" to -1 ). However, older children generated a group gradient; that is, responded maximally to $S+$ This interaction between age and stimuli may be seen in Fig. 2.

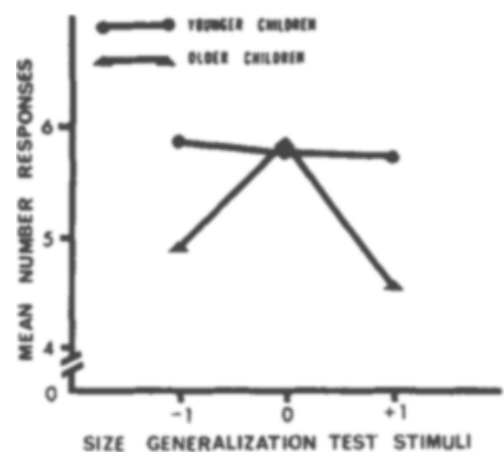

Fig. 2. Mean number of responses to size generalization test stimuli for younger and older children.

Examination of individual test patterns generated by the older children revealed that the group gradient was composed of two subgroups: One major group consisted of Ss who responded maximally to all stimuli, while another group was composed of Ss who responded to $S+$ only. Thus, the group gradient was not representative of individual patterns of responding.

\section{DISCUSSION}

The size generalization patterns obtained in Experiment 1 were in accord with the findings for line-orientation. That is, gradients were not established to absolute values of size stimulation. That is not to say, however, that size cues were not differentially attended to. Verbal responses during testing indicated that Ss discriminated size differences among the test stimuli. Generalization performance, however, showed that Ss responded maximally to all test stimuli as "vec." These results in combination suggest that although size was discriminated or attended to as a dimension it was not relevant or effective in mediating overt behavior in testing. The results of posttest questioning suggest that the effective stimulus or primary effective stimulus for some Ss was white, for others white and square, and for others white and black. Any or all of these cues could have mediated criterion performance during discrimination training.

Experiment 2 replicated the basic finding of a flat size generalization pattern independent of test method for young children. The results for the older children indicated a group gradient and is thus in agreement with previously reported generalization research with this age range. However, this finding would not appear to support a spread of associations hypothesis since individual $\mathrm{Ss}$ did not generate size gradients corresponding to the group function. Rather, the examination of individual patterns in relation to verbal data suggested that various aspects of the stimulus complex controlled overt behavior. For all younger children and most older children controlling stimuli such as white, square, and white and black yielded flat test patterns, while for some older children the controlling stimulus, apparently the size cue, led to a failure to respond to test stimuli.

The results of the present generalization experiments suggest that (1) during discrimination training, $\mathbf{S}$ discriminates several aspects or dimensions of a stimulus complex, and (2) that although several stimulus properties may be attended to and/or "learned" only some of these stimulus properties, apparently through a selection and association process, come to control overt behavior while other aspects do not.

\section{REFERENCES}

HEBERT, J. A., \& KRANTZ, D. L. Transposition: A reevaluation. Psychological Bulletin, 1965, 63, 244-257.

JEFFREY, W. E., \& SKAGER, R. W. Effect of incentive conditions on stimulus generalization in children. Child Development, 1962, 33, 865-870.

LANDAU, J. S. Postdiscrimination generalization in human subjects of two different ages. Journal of Experimental Psychology, 1968a, 76, 656-663.

LANDAU, J. S. Line-orientation generalization in children and adults as a function of the number of training trials. Psychonomic Science, 1968b, 13,219-220.

MEDNICK, S. A., \& LEHTINEN, L. E. Stimulus generabization as a function of age in children. Joumal of Experimental Psychology, 1957,53. 180-183.

SPIKER, C. C. The effects of number of reinforcements on the strength of a generalized instrumental response. Child Development, 1956a, 27, 37-44.

SPIKER, C. C. The stimulus generalization gradient as a function of the intensity of stimulus ligh ts. Child Development, 1956b, 27, $85-98$.

TEMPONE, V. J. Stimulus generalization as a function of mental age. Child Development, $1965,36,229.235$.

TEMPONE, V. J. Mediational processes in primary stimulus generalization. Child Development, 1966, 37, 687-696.

\section{NOTE}

1. I would like to thank the following nursery school directors for their kind cooperation in providing subjects: Agnes Short, of the Garden City Nursery School, Garden City, Long Island, New York; and Ruth Hawl, of the Hempstead ECO Day Care Center, Hempstead, Long Island, New York. 